FEDERAL RESERVE BANK OF SAN FRANCISCO

WORKING PAPER SERIES

\title{
EAD Calibration for Corporate Credit Lines
}

\author{
Gabriel Jiménez \\ Banco de España \\ Jose A. Lopez \\ Federal Reserve Bank of San Francisco \\ Jesús Saurina \\ Banco de España
}

January 2009

Working Paper 2009-02

http://www.frbsf.org/publications/economics/papers/2009/wp09-02bk.pdf

The views in this paper are solely the responsibility of the authors and should not be interpreted as reflecting the views of the Federal Reserve Bank of San Francisco or the Board of Governors of the Federal Reserve System. 


\title{
EAD Calibration for Corporate Credit Lines
}

\author{
Gabriel Jiménez \\ Banco de España \\ gabriel.jimenez@bde.es \\ Jose A. Lopez \\ Federal Reserve Bank of San Francisco \\ jose.a.lopez@sf.frb.org \\ Jesús Saurina \\ Banco de España \\ jsaurina@bde.es
}

Draft date: January 7, 2009

The views in this paper are solely the responsibility of the authors and should not be interpreted as reflecting the views of the Banco de España, the European Central Bank, the Federal Reserve Bank of San Francisco or the Board of Governors of the Federal Reserve System. Gabriel Jiménez is a senior economist at the Banco de España; Jesús Saurina is the head of the Financial Stability Department at the Banco de España; and Jose A. Lopez is a research advisor at the Federal Reserve Bank of San Francisco. 


\section{EAD Calibration for Corporate Credit Lines}

Managing the credit risk inherent to a corporate credit line is similar to that of a term loan, but with one key difference. For both instruments, the bank should know the borrower's probability of default (PD) and the facility's loss given default (LGD). However, since a credit line allows the borrowers to draw down the committed funds according to their own needs, the bank must also have a measure of the line's exposure at default (EAD). In fact, $\mathrm{EAD}$ is one of the key parameters used for regulatory capital calculations within the Basel II Framework. Yet, relatively few empirical studies of EAD for corporate credit lines have been published, mainly due to a lack of data. A primary goal of this article is to provide calibrated values for use in EAD calculations for corporate credit lines.

Our study is based on the Spanish credit register, which provides a census of all corporate lending within Spain over the last twenty years. The length and breadth of this dataset allows us to provide the most comprehensive overview of corporate credit line use and EAD calculations to date. Our analysis shows that defaulting firms have significantly higher credit line usage rates and EAD values up to five years prior to their actual default. Furthermore, we find that there are important variations in EAD values due to credit line size, collateralization, and maturity. While our results are derived from data for a single country, they should provide useful benchmarks for further academic, business and policy research into this under-developed area of credit risk management.

\section{$\underline{\text { Definitions and literature review }}$}

Bank credit lines are a major source of funding and liquidity for firms. For example, Sufi (2008) found that credit lines account for over $80 \%$ of the bank financing provided to U.S. public firms, while Kashyap et al. (2002) found that $70 \%$ of bank borrowing by U.S. small firms is through credit lines. For Spanish firms, the subject of our study, credit lines account for an average of $42 \%$ of firms' bank financing and $32 \%$ of banks' total new lending.

To set our terminology clearly, we define a corporate credit line as a loan commitment in which the borrower has the option to draw down funds up to the commitment amount under certain conditions. For risk management purposes, a bank's EAD through credit line $i$ at time $t$ for a default horizon $\tau$, which we denote as $\operatorname{EAD}_{\mathrm{it}}(\tau)$, is the sum of the actual drawn amount at time $t$ and a fraction of the undrawn amount, where that fraction takes into account the default horizon. This fraction is commonly known as the loan equivalent amount (LEQ) 
and is the key parameter in EAD estimation and calibration. ${ }^{1}$ Using notation,

$$
\operatorname{EAD}_{\mathrm{it}}(\tau)=\mathrm{DRAWN}_{\mathrm{it}}+\mathrm{LEQ}_{\mathrm{it}}(\tau) * \mathrm{UNDRAWN}_{\mathrm{it}}
$$

where DRAWN ${ }_{\text {it }}$ and UNDRAWN ${ }_{\text {it }}$ represent the monetary value of the drawn and undrawn portions of a credit line at time $t$. The sum of these two values is clearly the total commitment amount. For credit lines with a non-zero undrawn amount, LEQ for a default that occurs $\tau$ periods in the future is expressed algebraically as

$$
\operatorname{LEQ}_{i t}(\tau)=\frac{\text { DRAWN }_{i t+\tau}-\text { DRAWN }_{\text {it }}}{\text { UNDRAWN }_{\text {it }}}
$$

Since DRAWN $\mathrm{it}_{\mathrm{it}+\tau}$ is not observable at time $t$, it must be replaced with a forecast for operational purposes. Hence, the challenge in generating EAD values is to find reasonable LEQ estimates.

Three empirical studies providing calibrated LEQ estimates are publicly available. Asarnow and Marker (1995) present LEQ estimates based on credit lines issued by Citibank to publicly-rated North American firms over the five-year period from 1987 to 1992. They report an average LEQ value of just over $60 \%$ with a roughly downward sloping trend from $69 \%$ for AAA-rated firms to $44 \%$ for CCC-rated firms. The intuition behind this trend is that in case of default, lower-rated firms typically have already drawn down a reasonable portion of their credit lines and are less likely to drawn down as much of their remaining commitment as highly-rated firms.

The LEQ estimates provided by Araten and Jacobs (2001) are based on 408 credit facilities to 399 defaulted U.S. borrowers issued by the former Chase Manhattan Bank over the six-year period from 1994 to 2000. Their reported average LEQ is about 43\%. They examined LEQ values at several default horizons and found $\mathrm{LEQ}_{\mathrm{it}}(\tau)$ to be an increasing function of $\tau$, ranging from $33 \%$ at one year prior to default to $72 \%$ at five years prior. The intuition here is that as default approaches (i.e., as $\tau$ decreases), borrowers that eventually default are more likely to have drawn down more of their credit lines earlier. They also found that LEQs declined with risk ratings, but that a variety of other variables, such as

\footnotetext{
${ }^{1}$ See Moral (2006) for further technical discussion. Note that we ignore any net accrued, but as yet unpaid, interest and fees in this study.
} 
commitment size and borrower industry, did not impact their estimated LEQ values.

The study by Jacobs (2008) is the most comprehensive of the three, encompassing 3,281 defaulted instruments from 720 U.S. borrowers with public credit ratings over the period from 1985 through 2006. In addition to providing univariate analysis of the relationship between LEQ values and other variables related to the firm's balance sheet and the credit line's characteristics, the author estimates a multivariate model based on generalized linear regression. The average LEQ measure for the complete sample is $39 \%$. Across default horizons, he found that $\mathrm{LEQ}_{\mathrm{it}}(\tau)$ was a generally increasing function of $\tau$, ranging from $33 \%$ at one year prior to default to $48 \%$ at four years prior. However, the LEQ value declined to $26 \%$ at five years prior to default, perhaps in part due to the few datapoints available in the sample. Credit ratings also had a negative relationship with average LEQ values in this study, ranging from $76 \%$ for BBB-rated firms to $22 \%$ for D-rated firms. While commitment size and collateral rank had positive, but relatively small, effects on LEQ values, other firm characteristics, such as profit, did have a statistically significant effect.

\section{$\underline{\text { Our data and calibration methods }}$}

Our LEQ estimates are based on the Spanish credit register, which is known as the Central de Información de Riesgos (CIR), and is maintained by the Banco de España. The CIR contains information on all corporate loan commitments of more than $€ 6,000$ granted by any bank operating in Spain over the twenty-year period from 1984 to 2005; see Jiménez et al. (2008) for a more detailed description of the database and its coverage of corporate credit lines. The definition of default used in the CIR database is that the borrower has loan payments overdue by more than 90 days, which is the legal definition of default in Spain, or that it has been classified as a doubtful borrower by the bank (i.e., the lender believes there is a high probability of non-payment). As shown in Table 1, the number of defaults rose sharply during the recessionary period of 1993 and declined at a relatively slow pace until 2005.

Our database consists of new corporate credit. Despite the fact that most credit lines nominally have a maturity of one year or less, it is common to find them in the database again the following year with exactly the same characteristics (in particular, their commitment size) and changing only in the amount drawn. For our analysis, we assume it is the same credit line, and we classify the observations as having both short maturities and line ages greater than their recorded maturities. After filtering the data, our sample includes 696,445 credit lines granted to 334,442 firms by 404 banks. The commitment size has an interquartile range 
of between $€ 30,000$ and $€ 150,000$ with a median value of $€ 60,000$. Our sample clearly contains more small business loans than examined in the previously noted studies. Of these lines, 4,289 of them were granted to 4,094 firms that defaulted; these lines have an interquartile range of between $€ 30,000$ and $€ 96,000$ with a median value of $€ 48,000$. Figure 1 presents the histogram of our credit line usage rates across firms and time, where the usage rate RDRAWN $\mathrm{it}_{\mathrm{it}}$ is calculated as

$$
\text { RDRAWN }_{\text {it }}=\frac{\text { DRAWN }_{\text {it }}}{\text { DRAWN }_{\text {it }}+\text { UNDRAWN }_{\text {it }}} \text {. }
$$

While just over $23 \%$ of the credit line-year observations amass at the endpoints, the remaining $77 \%$ are distributed almost symmetrically around the median value of $50 \%$.

When analyzing credit line usage rates, we find that firms that default on their credit lines draw down more funds than firms that do not default, even up to five years before the default year; see Jiménez et al. (2008) for complete details of this analysis. At five years prior, the average usage rate for defaulting firms is about $25 \%$ higher than that of nondefaulting firms. As default approaches, these firms draw down their credit lines at an increasing rate. At the default year, the average usage ratio for defaulting firms is $75 \%$ larger than that for non-defaulting. The empirical insight that defaulting firms exhibit higher usage rates up to five years prior to defaulting suggests a potentially important link between PD and EAD modeling.

\section{$\underline{\text { LEQ calibration results }}$}

As mentioned previously, generating reasonable EAD values for credit risk management purposes requires accurate LEQ estimates. ${ }^{2}$ Using the defaulted credit lines in our dataset, we generate average LEQ estimates for several default horizons and other relevant categories. Note that the LEQ values for certain credit lines may fall outside the unit interval (i.e., be negative or greater than 100\%) due to data issues, and in these cases, we round these values to the appropriate unit interval endpoint. ${ }^{3}$

\footnotetext{
${ }^{2}$ Note that another methodology frequently employed by practitioners is to generate LEQ estimates as the coefficient of a linear regression without a constant term of $\left(\right.$ RDRAWN $_{i t \tau}-$ RDRAWN $\left._{i t}\right)$ on $\frac{\text { UNDRAWN }_{i t}}{\text { COMMIT }_{i t}}$; see Moral (2006) for further details. The patterns of the LEQ values derived from this procedure as applied to our dataset are similar to those presented here, although their level is roughly ten percentage points higher.
} 
The average LEQ value for the entire dataset is $59.6 \%$, which is in line with the value reported by Asarnow and Marker (1995) and higher than that reported by Araten and Jacobs (2001) as well as Jacobs (2008). Looking at our LEQ ${ }_{i t}(\tau)$ estimates for $\tau \in[1,5]$ as presented in Figure 2, we find an upward sloping pattern, as in Araten and Jacobs (2001) as well as Jacobs (2008). However, the magnitudes of our estimates are higher and range from $48 \%$ at one year prior to default to $76 \%$ at five years prior to default. In other words, in our dataset, firms that will default on their credit lines in five years time can be expected to draw down, on average, about three-quarters of their undrawn commitments, and this value declines to $50 \%$ in the year prior to default.

We also find that the commitment size, collateralization and maturity of the credit lines has an effect on the calibrated $\mathrm{LEQ}_{\mathrm{it}}(\tau)$ patterns. As shown in Figure 3 and Table 2, the largest credit lines (i.e., the fourth size quartile) have the lowest LEQ values at all default horizons, perhaps since the larger firms that can get larger credit lines from their banks have access to other funding sources and are less likely to use their credit lines, even as default approaches.

Regarding collateral, higher-quality borrowers should be willing to provide collateral as a signal of their confidence in their repayment ability, as discussed by Jiménez et al. (2006). This assumption would suggest lower LEQ values as these borrowers would be less likely to draw down their lines, even if they eventually default, in order to protect their collateral from being seized. Figure 4 and Table 3 present empirical results that support this hypothesis. While the average $\mathrm{LEQ}_{\mathrm{it}}(\tau)$ values at the longer default horizons are essentially the same, they are significantly different at the $1 \%$ significance level for the default horizons from one to three years. The difference is particularly stark at one year prior to default where uncollateralized lines see over half of their available commitments drawn down, whereas collateralized lines only experience a $30 \%$ drawn rate, on average.

Figure 5 and Table 4 present the LEQ estimates for credit lines with maturities greater than and less than (or equal to) one year. Again, the average $\mathrm{LEQ}_{\mathrm{it}}(\tau)$ values at the longer default horizons are indistinguishable, but they are significantly different for the shorter horizons. The LEQ estimates for the longer-term credit lines are lower, suggesting that higher-quality firms that are able to get such longer commitments from their lenders are less

\footnotetext{
${ }^{3}$ See Jacobs (2008) for further discussion of alternative LEQ methods.
} 
likely to draw down these funds, even in light of a pending default. In contrast, lower-quality firms that can only access shorter-term funding are much more dependent on these funds and thus more likely to draw down these credit lines.

\section{$\underline{\text { Conclusion }}$}

Corporate credit lines are a key product for banks, and the management of their inherent credit risks requires calibration of their EAD parameters. Using the credit register maintained by Banco de España, we construct an extensive database of defaulted corporate credit lines over a twenty-year period to calibrate the key LEQ component of these EAD values at various default horizons. Our results show that a variety of factors - such as commitment size, collateralization and maturity - influence the LEQ calibrations. Our conclusion is that banks must address these factors in their EAD calibration processes, even if regulatory capital guidelines do not explicitly require it. Our results should provide reasonable starting values for most of these calibrations, but future work across different countries and time periods is necessary. 


\section{References}

Araten, M. and Jacobs, M., Jr., 2001. "Loan Equivalents for Revolving Credits and Advised Lines," The RMA Journal, May, 34-39.

Asarnow, E. and Marker, E., 1995. "Historical Performance of the U.S. Corporate Loan Market: 1988-1993," Commercial Lending Review, 10(2), 13-32.

Jacobs, M., Jr., 2008. “An Empirical Study of Exposure at Default,” Manuscript, Office of the Comptroller of the Currency, U.S. Department of the Treasury.

Jiménez, G., Lopez, J.A. and Saurina, J., 2008. "Empirical Analysis of Corporate Credit Lines", Review of Financial Studies, forthcoming.

Jiménez, G., Salas, V. and Saurina, J., 2006. "Determinants of Collateral”, Journal of Financial Economics, 81, 255-281.

Kashyap, A. Rajan, R. and Stein, J., 2002. "Banks as Liquidity Providers: An Explanation for the Co-existence of Lending and Deposit-Taking," Journal of Finance, 57, 33-73.

Moral, G., 2006. "EAD Estimates for Facilities with Explicit Limits" in Engelmann, B. and Rauhmeier, R., eds. The Basel II Risk Parameters: Estimation, Validation, and Stress Testing. New York: Springer, pages 197-242.

Sufi, A., 2008. "Bank Lines of Credit in Corporate Finance: An Empirical Analysis," Review of Financial Studies, forthcoming. 
Table 1.

Number of defaulted credit lines in our sample

\begin{tabular}{rr} 
Year & \# of defaulted credit lines \\
\hline 1986 & 45 \\
1987 & 58 \\
1988 & 97 \\
1989 & 110 \\
1990 & 167 \\
1991 & 210 \\
1992 & 350 \\
1993 & 485 \\
1994 & 434 \\
1995 & 377 \\
1996 & 356 \\
1997 & 267 \\
1998 & 262 \\
1999 & 204 \\
2000 & 224 \\
2001 & 125 \\
2002 & 124 \\
2003 & 121 \\
2004 & 110 \\
2005 & 173 \\
\hline
\end{tabular}

Figure 1.

Histogram of the corporate credit line usage rates

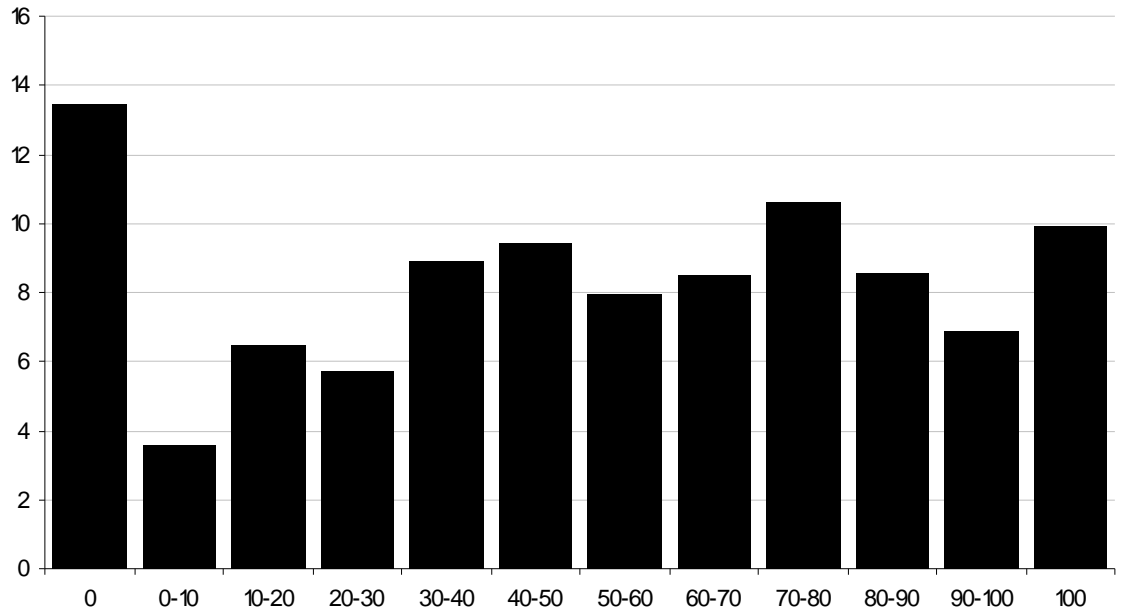

RDRAWN $_{\mathrm{it}}(\%)$ 
Figure 2.

Average $L_{E Q} Q_{i t}(\tau)$ for defaulted credit lines

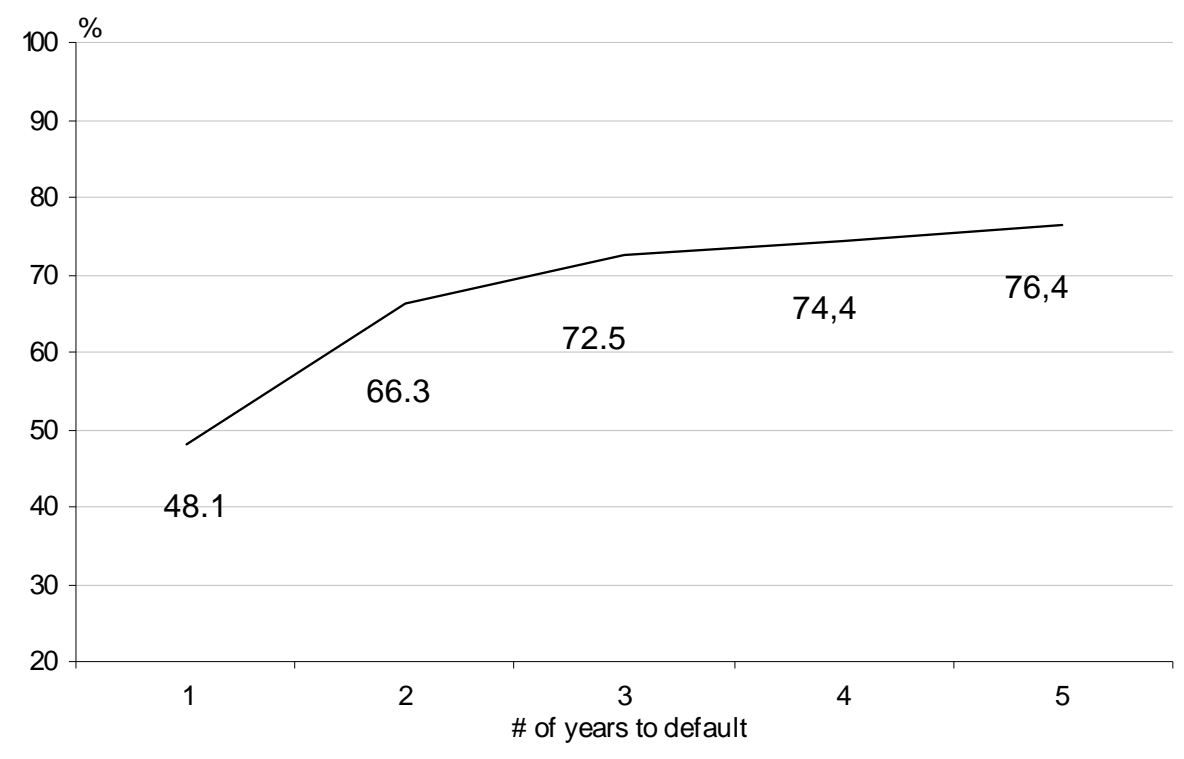




\section{Figure 3.}

Average $\mathrm{LEQ}_{\mathrm{it}}(\tau)(\%)$ for defaulted credit lines depending on total commitment size

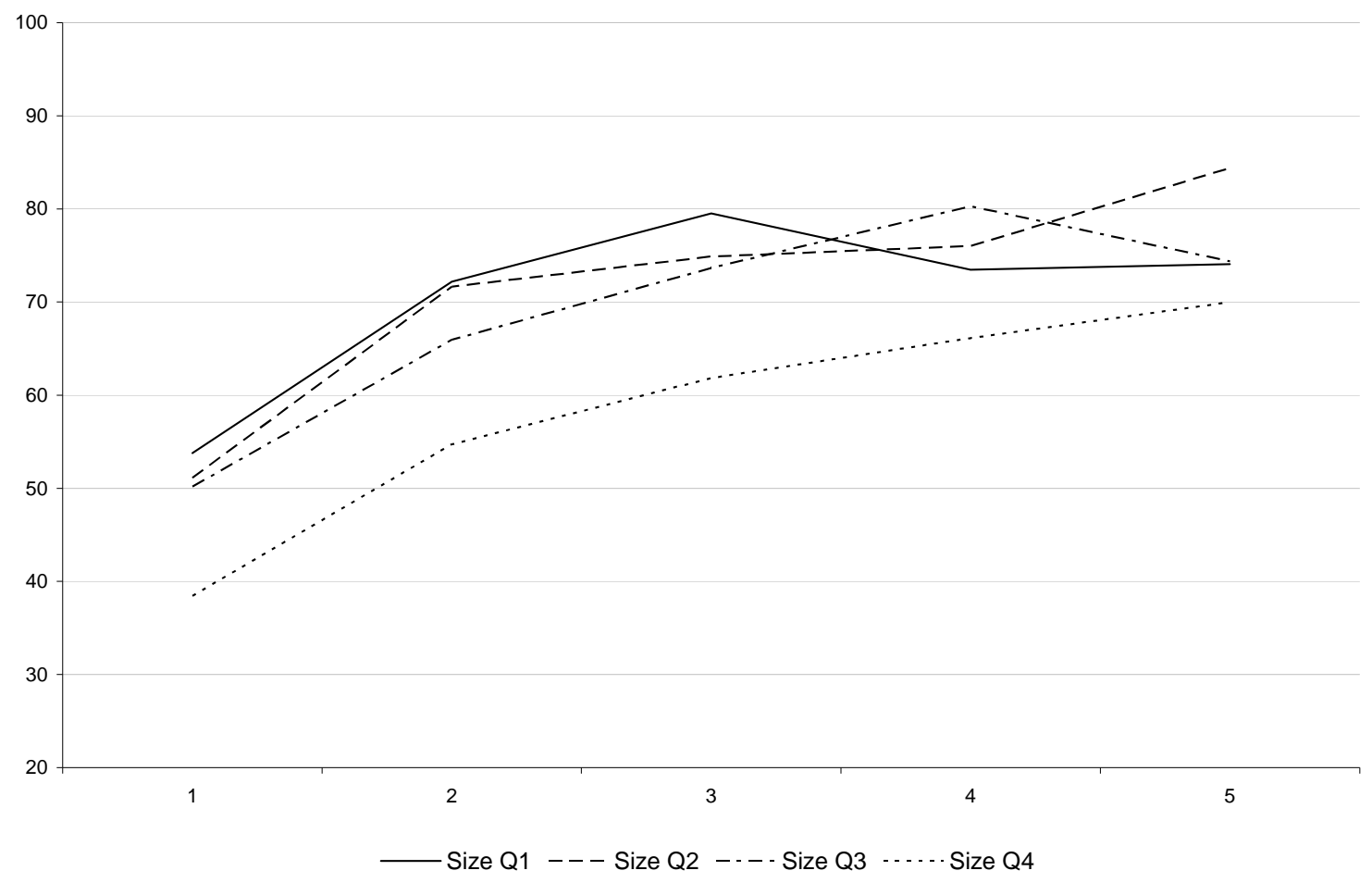

Note: $Q_{i}$ denotes the $i^{\text {th }}$ quartile of the total commitment size of the credit line. The endpoints of the four quartiles are $[€ 6,000, € 36,000]$ for Q1, $[€ 37,000, € 65,000]$ for Q2, $[€ 66,000, € 139,000]$ for Q3, and $[€ 140,000, € 69,513,000]$ for Q4.

Table 2.

Average $L_{E Q}(\tau)(\%)$ for defaulted credit lines depending on total commitment size

\begin{tabular}{rrrrr}
$\begin{array}{c}\text { \# years } \\
\text { to default }\end{array}$ & Size Q1 & Size Q2 & Size Q3 & Size Q4 \\
\hline $\mathbf{1}$ & 53.8 & 51.1 & 50.2 & 38.4 \\
$\mathbf{2}$ & 72.2 & 71.7 & 65.9 & 54.7 \\
$\mathbf{3}$ & 79.5 & 74.9 & 73.7 & 61.8 \\
$\mathbf{4}$ & 73.5 & 76.0 & 80.3 & 66.1 \\
$\mathbf{5}$ & 74.1 & 84.4 & 74.4 & 70.0 \\
\hline
\end{tabular}

Note: Qi denotes the $\mathrm{i}^{\text {th }}$ quartile of the total commitment size of the credit line. The endpoints of the four quartiles are $[€ 6,000, € 36,000]$ for Q1, [€37,000, €65,000] for Q2, [€66,000, €139,000] for Q3, and $[€ 140,000, € 69,513,000]$ for Q4. 
Figure 4.

Average $L E Q_{i t}(\tau)$ for defaulted credit lines depending on pledged collateral

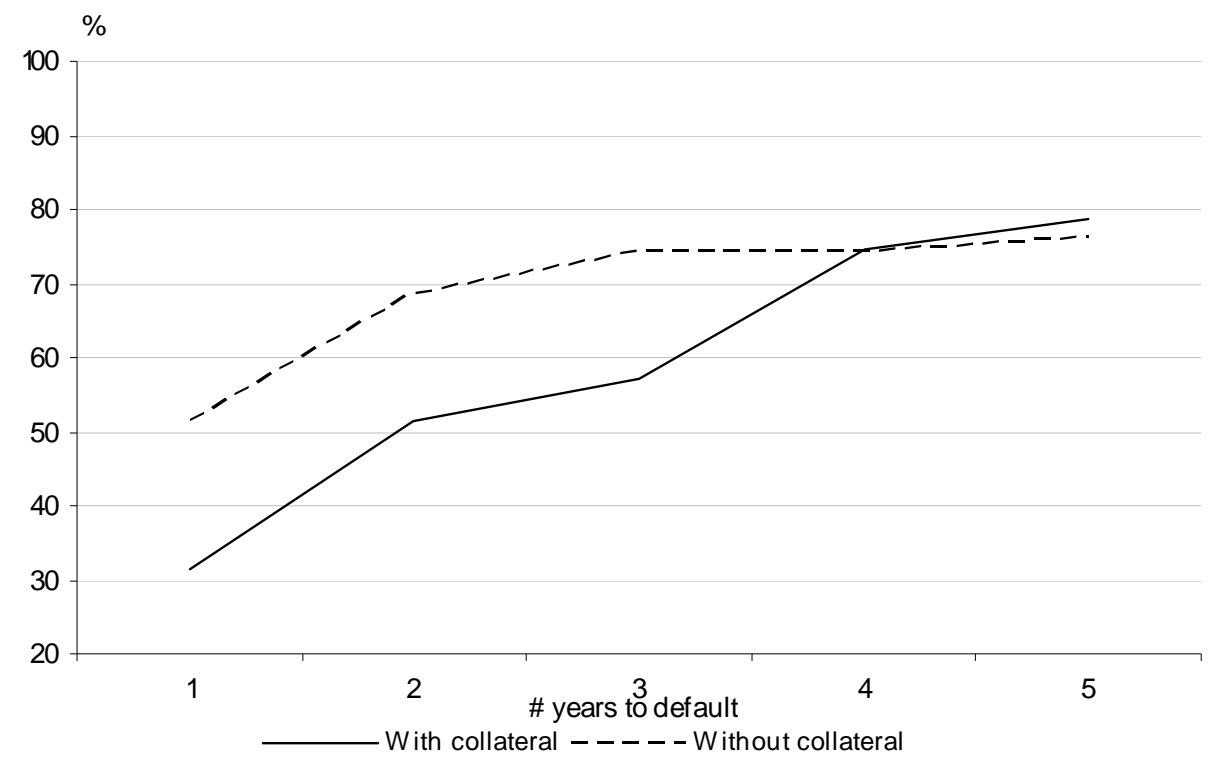

Table 3.

Average $L E Q_{i t}(\tau)(\%)$ for defaulted credit lines depending on pledged collateral

\begin{tabular}{rrrrr}
$\begin{array}{c}\text { \# years } \\
\text { to default }\end{array}$ & $\begin{array}{c}\text { Without } \\
\text { collateral }\end{array}$ & \multicolumn{2}{c}{$\begin{array}{c}\text { With } \\
\text { collateral }\end{array}$} & \multicolumn{2}{c}{ Mean test } \\
\hline $\mathbf{1}$ & 51.5 & 31.4 & 9.14 & $0.00{ }^{* \star}$ \\
$\mathbf{2}$ & 68.6 & 51.5 & 5.13 & $0.00{ }^{* \star}$ \\
$\mathbf{3}$ & 74.4 & 57.1 & 3.36 & $0.00{ }^{* \star}$ \\
$\mathbf{4}$ & 74.4 & 74.5 & 0.00 & 1.00 \\
$\mathbf{5}$ & 76.3 & 78.9 & -0.17 & 0.87 \\
\hline
\end{tabular}


Figure 5.

Average $L E Q_{i t}(\tau)$ for defaulted credit lines depending on maturity

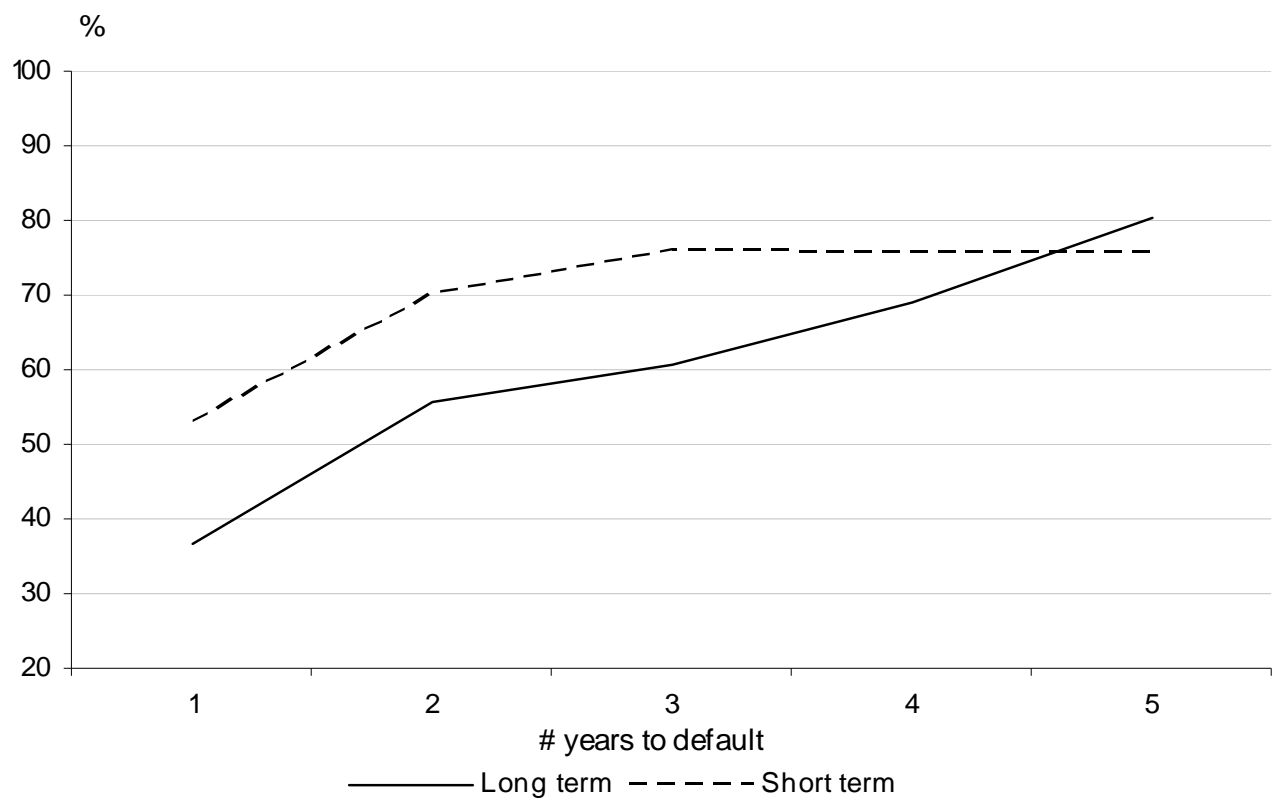

Table 4.

Average $\operatorname{LEQ}_{\mathrm{it}}(\tau)(\%)$ for defaulted credit lines depending on maturity

\begin{tabular}{|c|c|c|c|c|}
\hline $\begin{array}{l}\text { \# years } \\
\text { to default }\end{array}$ & $\leq 1$ year & $>1$ year & \multicolumn{2}{|c|}{ Mean test } \\
\hline$\overline{1}$ & 53.1 & 36.7 & 8.74 & $0.00 * \star \star$ \\
\hline 2 & 69.9 & 55.6 & 5.42 & $0.00 * * *$ \\
\hline 3 & 75.9 & 60.6 & 4.05 & $0.00 * * *$ \\
\hline 4 & 75.7 & 68.9 & 1.25 & 0.21 \\
\hline 5 & 75.8 & 80.4 & -0.65 & 0.52 \\
\hline
\end{tabular}

